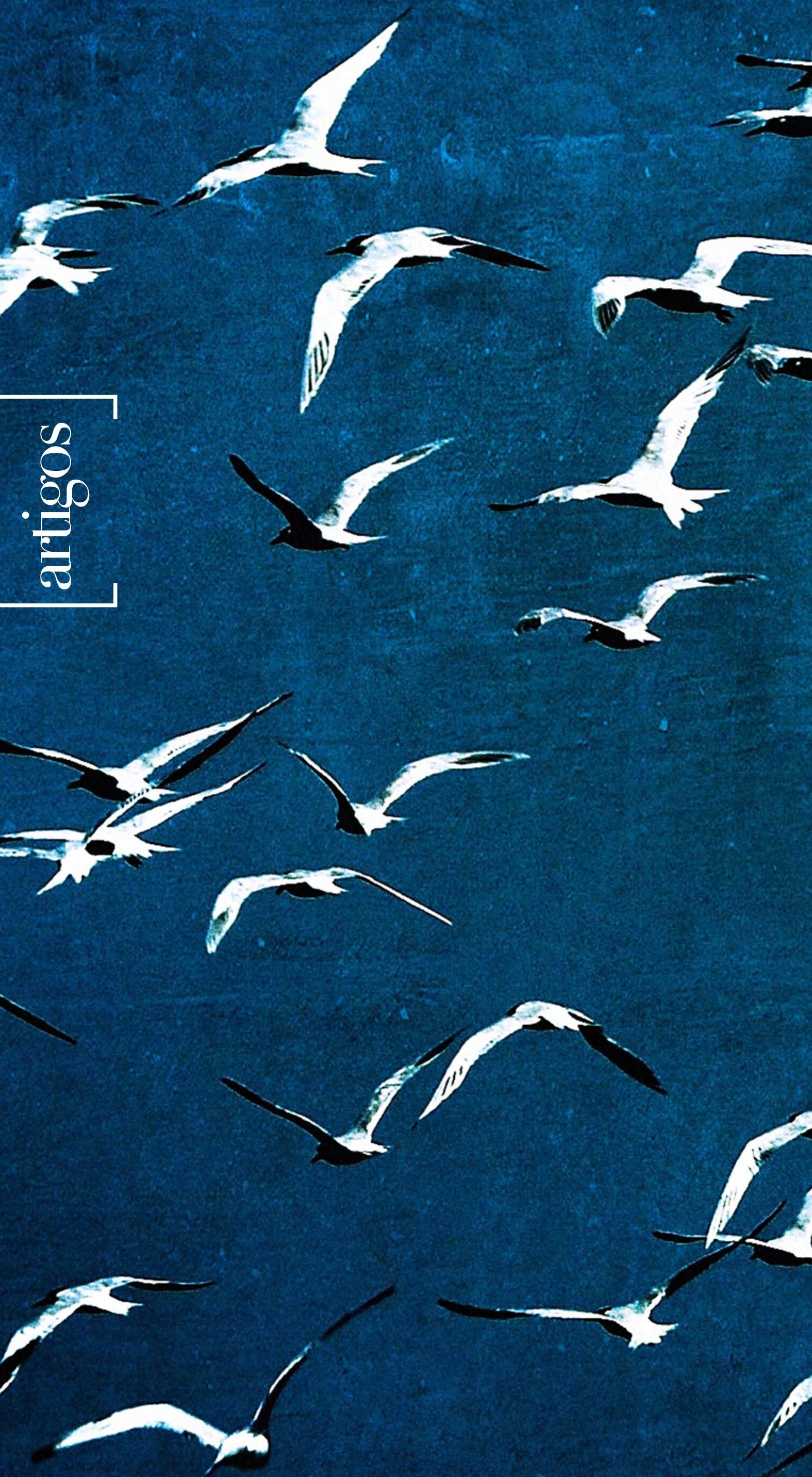




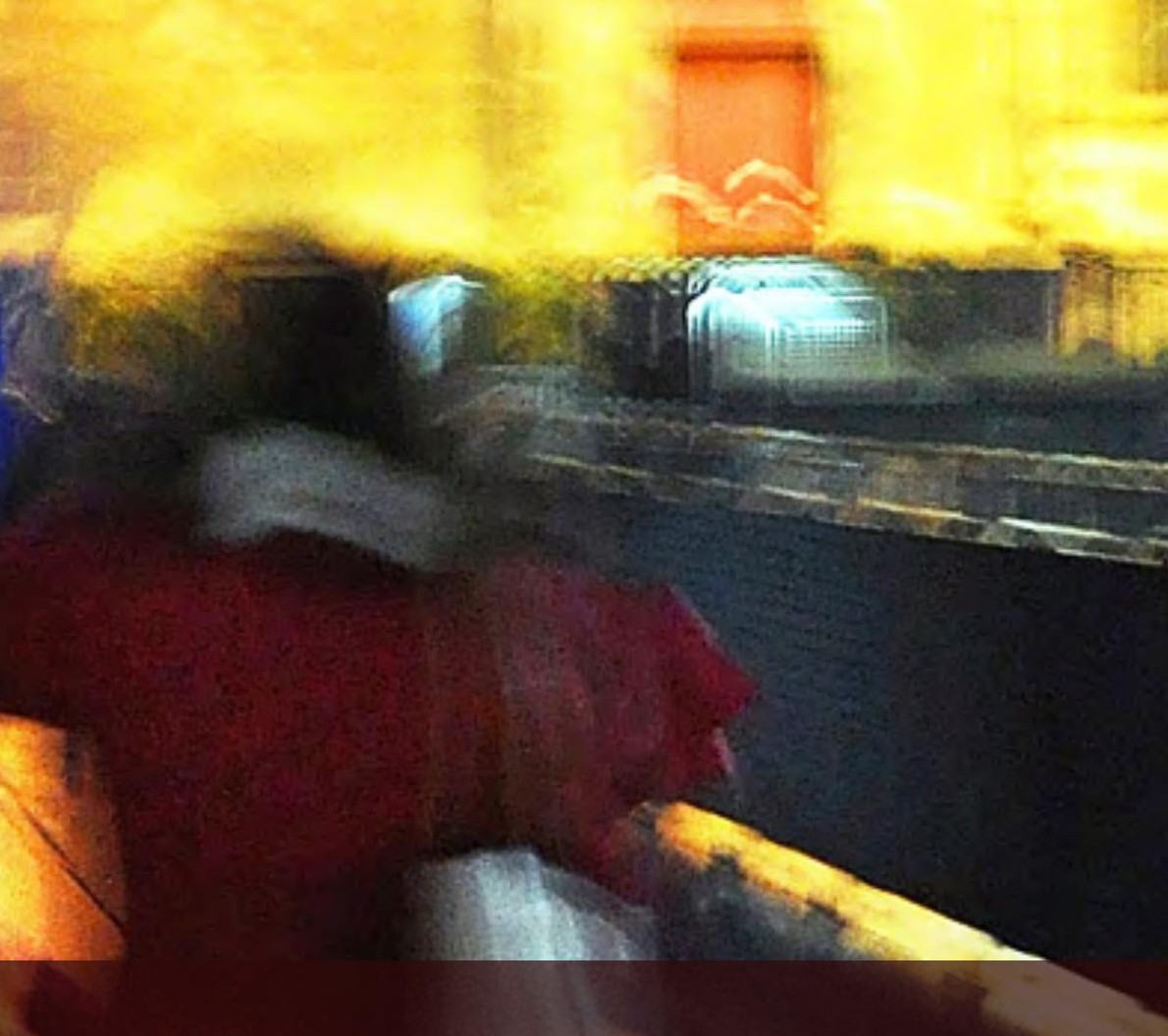

\section{A roupa em conexão com ações poéticas e políticas'}

Dress in connection with

poetic and political actions

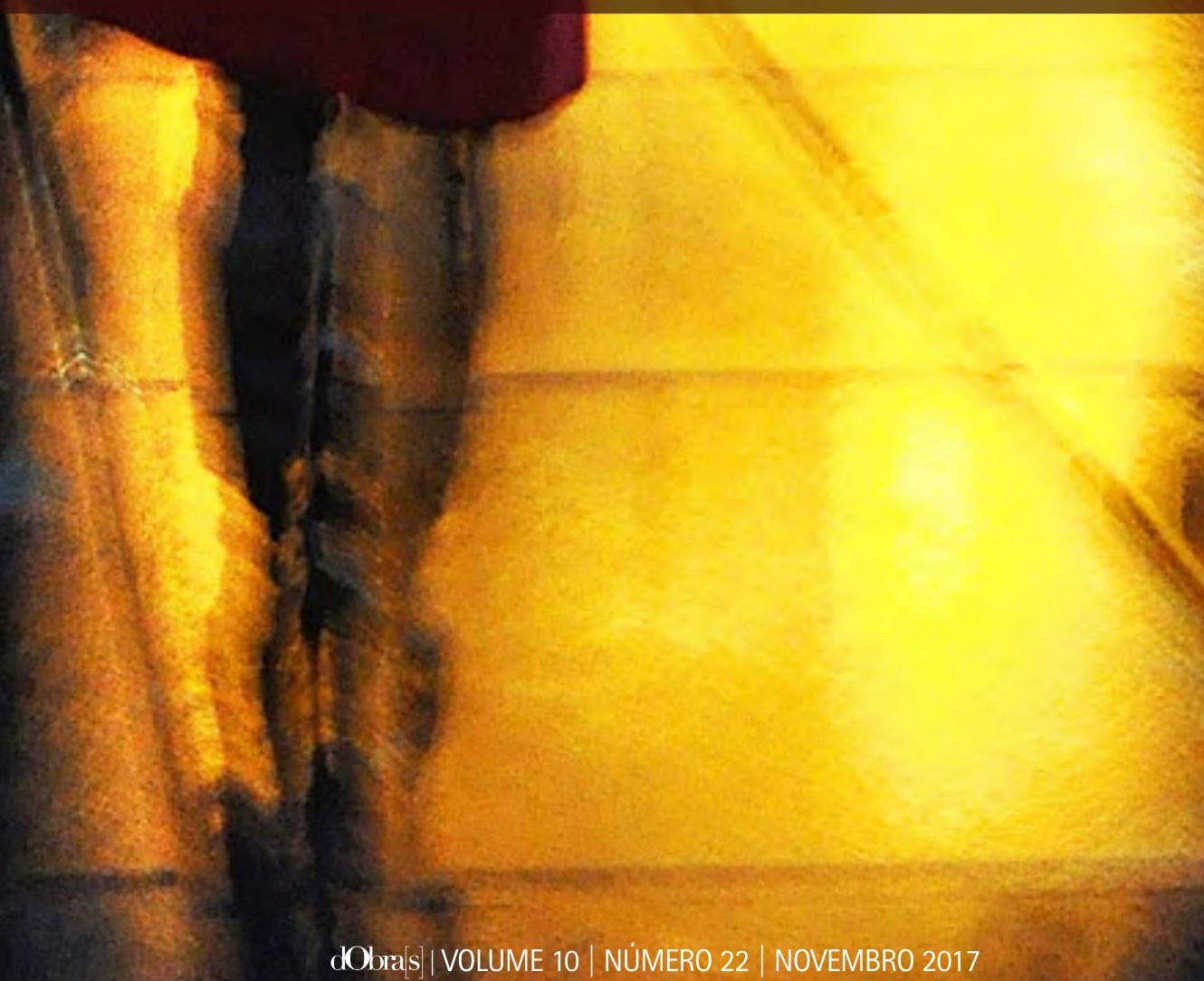




\section{[ROSANE PRECIOSA SEQUEIRA]}

Poeta, ensaísta e professora; doutora em Psicologia Clínica pela PUC-SP; atua no programa de pós-graduação em Artes, Cultura e Linguagens do Instituto de Artes e Design da Universidade Federal de Juiz de Fora - UFJF.

\section{E-mail: rosane_preciosa@yahoo.com.br}

\section{[RITA MORAIS DE ANDRADE]}

Dedicada a estudar o vestir no Brasil; doutora em História pela PUC-SP e professora do programa de pós-graduação em Arte e Cultura Visual da Faculdade de Artes Visuais da Universidade Federal de Goiás - UFG.

\section{E-mail: ritaandrade@hotmail.com}

[resumo] Neste artigo, buscamos problematizar as roupas como territórios de criação que engendram narrativas vestiveis mais autônomas, mais insubmissas aos modos hegemônicos de criá-las, e que são amplamente disseminados pelas mídias. Percebe-se que cada vez mais artistas, estilistas e ativistas vêm se apropriando das roupas como suporte para suas experimentações, fazendo ventilar na existência importantes questionamentos éticos, estéticos e políticos. Exploramos certos modos de vestir nas manifestações de rua, seguindo a Primavera Árabe, e também no trabalho de artistas, como Flávio de Carvalho, e criadores, como Lika Stein. A partir disso, discutimos o anonimato traduzido na aparência como uma ética-estética congruente às reivindicações sociais que atualmente transcendem questões nacionais e indicam novas perspectivas de estudos relativos à moda.

\section{[palavras-chave]}

poéticas do vestir; moda e política; manifestações de rua.

[abstract] In this paper we seek to problematize dress as creative territories, which generate more autonomous, insubmissibles, wearable narratives in opposite to hegemonic ways of creating them as widely disseminated by the media. More and more artists, stylists and activists have been appropriating clothes as a means to support their experiments, making important ethical, aesthetic and political remarks. We explored certain ways of dressing in street manifestations following the Arab Spring, and also seen in the work of artists like Flávio de Carvalho and creators such as Lika Stein. From this, we discuss the anonymity translated into appearance as an ethics-aesthetic which is congruent to social demands that currently transcend national issues and indicate new perspectives to fashion.

[keywords] poetics of dress; fashion and politics; popular claimings. 
Em junho de 2013, alastrou-se, por algumas capitais brasileiras, uma série de manifestações políticas convocadas pelas redes sociais que levaram multidões às ruas. Mobilizadas a princípio pelo Movimento Passe Livre, constituído em 2005 no Fórum Social Mundial de Porto Alegre, cuja reivindicação era barrar o aumento das passagens de transporte coletivo na cidade de São Paulo, os protestos se disseminaram por outras cidades e ganharam expressões reivindicatórias que ultrapassaram a convocação inicial. Foi nesse contexto que surgiram grupos de manifestantes identificados como Anonymous, que se autodenominam hacktivistas e black blocs'. Em comum, há o fato de que seus integrantes usam máscaras e são acusados de comandarem ações violentas que culminam em depredação do patrimônio público e privado.

Sobre os mascarados black blocs, contamos com informações veiculadas o tempo todo na mídia impressa e televisiva que a eles se referem como "baderneiros", a exemplo da seguinte matéria do jornal 0 Globo (versão digital), 9 ] às $5 \mathrm{~h}$ de 11 de outubro de $2013^{3}$ :

\begin{abstract}
Esta semana, no Centro do Rio, pelo menos cem Black Blocs foram responsabilizados por um quebra-quebra durante um protesto de professores. No dia seguinte foi feito o balanço da baderna: 12 agências bancárias depredadas, uma loja de telefonia arrombada e saqueada, além de praticamente todos os pontos de ônibus [...] danificados. (0 GLOBO, 2013)
\end{abstract}

Uma fotografia, entre tantas publicadas dos manifestantes em meados de 2013, chamou a nossa atenção pelo fato de constituir uma imagem da juventude urbana representada pela mobilidade ágil de uma pessoa com um skate carregado às costas, pernas largamente espaçadas, flagradas no movimento da corrida, pela fotografia de Ricardo Moraes para a agência Reuters ${ }^{4}$, e o rosto quase totalmente coberto pelo que aparenta ser uma camiseta. Essa imagem parece estranha pela presença da máscara improvisada, já vista em tantas outras manifestações populares também em outros paises, como na Primavera Árabe.

A capa emblemática da revista Time, Person of the year (Figura 1), destacou o rosto anônimo de um manifestante coberto por uma máscara feita com um gorro e um tecido, talvez uma camiseta, que encobre o rosto deixando apenas os olhos livres. 


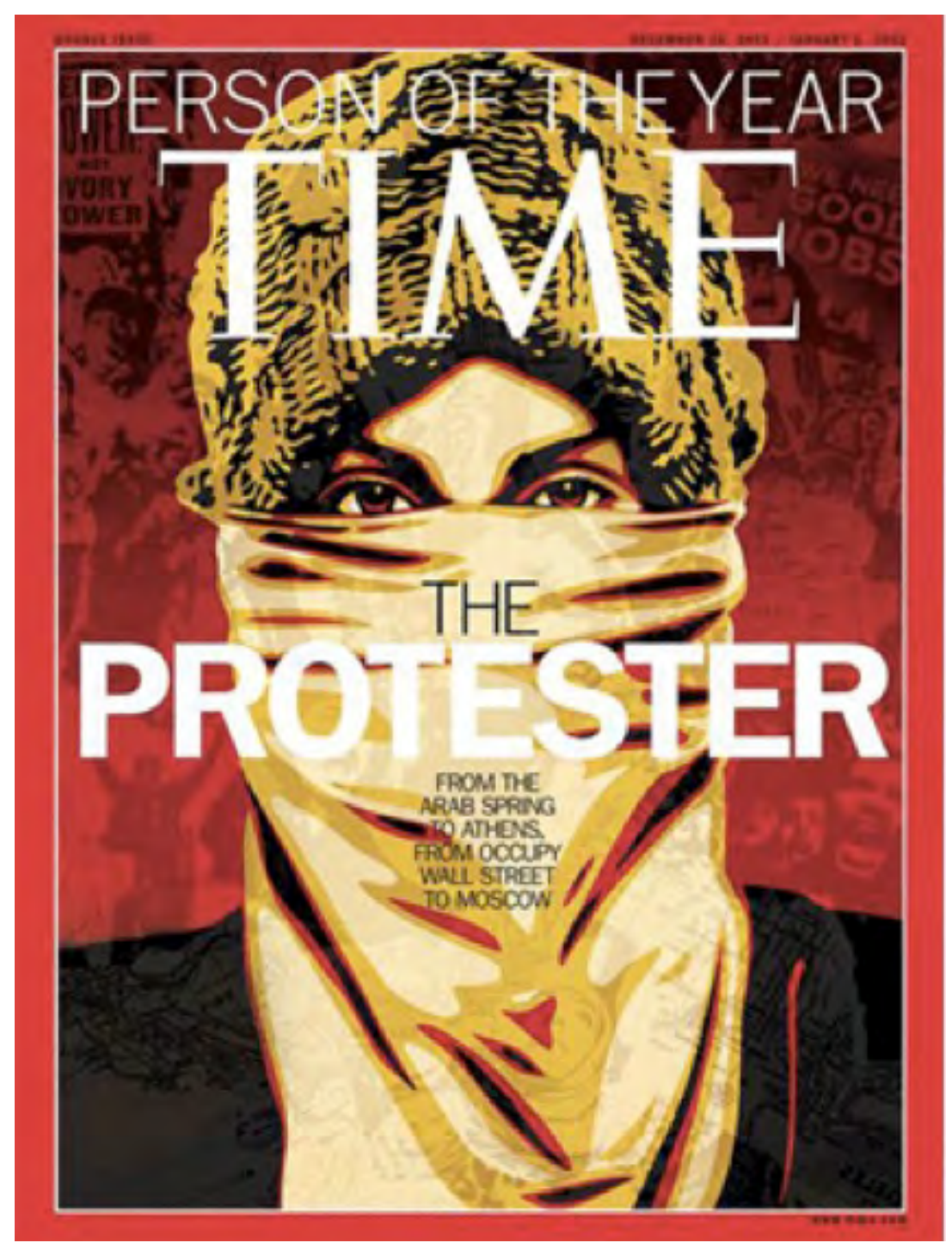

Figura 1 - Capa da revista Time: Person of the year, 26 dez. 2011, v. 178, n. 25. A edição foi dedicada a analisar os protestos que ficaram conhecidos como Primavera Árabe.

Fonte: Time, $2011^{5}$.

É indisfarçável o incômodo causado por essa legião de mascarados que se comporta de maneira excessiva, desestabilizando a ordem, desconcertando e também atemorizando por meio de sua aparência, exatamente porque sempre despachamos uma imagem chapada que deve corresponder àquela que fazemos de alguém, nesse caso, de quem vai às ruas para protestar. Mas e se 0 que vemos não corresponde ao catálogo de imagens prontas que estocamos?

Para além do fato de que uma máscara resguarda um sujeito de ser identificado, reconhecido, dando-lhe temporariamente um desejável anonimato em algumas circunstâncias, talvez seja oportuno refletirmos um pouco sobre a máscara no que ela traz de potência para se pensar em desvios de valores dominantes que orientam o campo social. A máscara é disfarce e também uma possibilidade de desinvestir do rosto, da identidade, de uma certa humanidade prescrita.

Se no lugar do rosto encontramos uma máscara, como abordar esse rosto? Você olha para ele e não vê a que família de rostos pertence. Um 
rosto inabordável, indecifrável. Algo insuportável para nós, que somos viciados em rostos, buscando decifrar emoções demasiadamente humanas por detrás deles. Afinal, um corpo aprende cedo a ter um rosto e nele reconhece sua identificação, seu pertencimento à cultura. Há sempre uma expectativa de que ele seja desvendado. É o que não acontece quando, no lugar do rosto, vemos outras paisagens, outros projetos de existência, suscitados por desejos nômades, descodificados e, portanto, inclassificáveis, incapturáveis a partir de uma lógica mais acomodada. 0 desconforto, então, provém de não saber o que pretende aquele rosto de nós.

0 jornal 0 Globo, de 11 de outubro de 2013, tratou logo de publicar não só um quadro com as conexões que os black blocs mantêm com outros grupos pelo mundo, bem como os caracterizou como jovens, na maioria com menos de 25 anos, dando ênfase aos trajes usados nas manifestações:

[...] Quando as pessoas vão em massa às ruas, elas estão celebrando possibilidades de fertilidade de vida. Elas comem, bebem, fazem teatro, fazem amor e apreciam a companhia umas das outras. Elas colocam máscaras e fantasias, levantam e movem bandeiras, e constroem efígies não meramente para disfarçar ou embelezar seus eus ordinários, ou para ostentar o exorbitante, mas também para expressar a multiplicidade de cada vida humana. (SCHECHNER, 2012, p. 157)

Ao ocupar as ruas para libertá-las da ordem demasiada, o inesperado pode acontecer. Dai o espanto diante de fabulações imprevistas que transtornam os costumeiros referenciais. A começar pelo vestuário, espécie de máscara corpórea que nos possibilita acessar outros de nós mesmos ao saltarmos para espaços que estão fora de nós. É todo um campo social que se vê interrogado esteticamente, politicamente, mediante as roupas que usamos. Patrice BolIon, em seu livro A moral da máscara (1993), nos introduz a um universo de múltiplas aparências que, ao longo da história, contestaram visões de mundo homogeneizantes, normativas, que recorreram à força da vestimenta para afirmar desvios, esquivando-se de sentidos de mão única. Ele afirma:

Sempre existiram individuos [...] que se expressassem e se afirmassem através de um estilo [...]. Homens e certamente mulheres também - que pretendem com sua aparência contestar um estado de coisas, uma escala de valores, uma hierarquia de gostos, uma moral, hábitos, comportamentos, uma visão de mundo ou um projeto, tais como são refletidos pelo traje dominante, pelo estilo obrigatório ou pela referência estética comum da sociedade em que vivem [...] (BOLLON, 2005, p. 11)

Curiosamente, a roupa é estigmatizada como algo frivolo, mas não para olhares mais atentos e talvez sensiveis - citemos o poeta Charles Baudelaire, cronista da modernidade que ousou mergulhar nas ruas e delas extrair a beleza fugaz dos passantes. A roupa ganha, na análise de Bollon (2005), uma 
dimensão que nos interessa muito enfatizar: a de que é preciso percorrer as superficies e nelas buscar as inscrições transitórias. Buscar decifrar não o que são aqueles corpos vestidos, mas o que estão sendo. Um modo de pensar que acata o fluxo da vida, os modos de agir que revelam até o mais perturbador, porque não estão dados a priori e porque atacam a temporalidade linear da moda. Os gestos desencadeados pelas roupas encontram seu sentido na medida em que performam no espaço. Podem aderir às determinações mais cristalizadas de um campo social, mas também podem quebrar seus roteiros mais consolidados, instaurando outras realidades possiveis.

Se o próprio cotidiano é habitado por signos sociais, culturais, políticos e estéticos tão heterodoxos, dificilmente poderemos encontrar respostas únicas em um território infestado de práticas tão contrastantes. A despeito de que se elejam alguns signos, que se tornam paradigmáticos e em torno deles força-se uma consensualidade, a partir de discursos publicitários bem amarrados, ainda assim, o imprevisto pode irromper. Relembremos Michel de Certeau (2003) ao nos falar das pequenas astúcias praticadas pelos sujeitos em seu cotidiano, que escapam aos modos disciplinares de existir.

A ideia que buscamos explorar aqui é a de que há movimentos sociais em curso de dimensões globais, mas com particularidades locais, que colocam a roupa ou o vestir-se para a rua/mundo como uma estratégia especial de experimentar o coletivo, o corpo social. Nesse movimento dos black blocs, apresentado acima brevemente, de demonstrações públicas de insatisfação com algumas soluções políticas para problemas atuais e outros antigos que persistem, parece haver uma ação distinta para escolher o que vestir, de modo que o que se veste e como se veste torna-se peça importante, fundamental, na reivindicação. Assim, encontramos na multidão, que se formou durante as manifestações públicas, um espectro heterogêneo e visualmente desafinado de invenções de trajes e modos de vestir que revelam, simultaneamente, desafios da convivência urbana e da herança colonial que adensa os problemas sociais. Sem escolher, a partir de um cardápio da moda vigente, trajar-se para reivindicar essas questões sociais, parte de um rol de referências de imagens que ziguezagueiam no tempo e no espaço.

Na conferência de abertura da $23^{\mathrm{a}}$ Reunião Internacional da Associação Internacional de Museus - ICOM, na cidade do Rio de Janeiro, em agosto de 2013, o historiador Ulpiano Bezerra de Menezes finalizou sua apresentação para uma audiência internacional com o que pareceu uma provocação pertinente. Ele disse: "Bem-vindos a nosso país tropical!". Com o título 0 museu e a condição humana: o horizonte sensorial, o historiador falou da multiforme cultura brasileira e, rejeitando os estereótipos aos quais chamou de turísticos sobre o Brasil (trópico, calor, caipirinha, praia e sol), propôs que o lugar essencial dos museus em nossas vidas deriva da potência de eles serem uma plataforma estratégica para compreender a condição humana em todas as suas formas, a começar pelo seguinte "Temos um corpo", o que significa atentar para uma nova realidade na qual dar sentido ao mundo implica interpretá-lo como realidade sensivel. Podemos emprestar essa análise feita sobre os mu- 
seus para pensar as manifestações populares por todo o país e considerar a atuação do corpo nas novas configurações sociais que estão tomando forma, e parecem se distanciar das fórmulas mais conhecidas, a que Ulpiano chamou de questões operacionais e normativas que precisam ser abandonadas para dar lugar a territórios de atuação.

A questão do museu talvez não esteja tão afastada do nosso tema. Afinal, a máscara - que está no museu como no Carnaval e nas ruas - talvez seja o símbolo mais expressivo da manifestação. Durante os protestos de junho de 2013, aos quais já nos referimos anteriormente, pudemos ver um grupo de pessoas improvisando performances contra a proibição do uso de máscaras durante as manifestações públicas. Ali identificamos símbolos visuais que, de certa forma, alinham questões dispares e variadas em montagens inusitadas: há um cocar, que representa o índio e suas questões singulares, mas também comparecem o negro, a mulher, a cultura estrangeira disseminada (que identificamos na camisa polo vestida por um dos manifestantes) e a justiça que, nesse contexto, dá ensejo a uma crítica social contundente ${ }^{6}$. Eram manifestantes mascarados protestando na Assembleia Legislativa do Rio de Janeiro contra um projeto de lei que proibe o uso de máscaras em protestos.

A defesa da máscara como um instrumento legítimo de reivindicação social é algo para se prestar atenção. 0 seu uso parece amplificar os signos que marcam o descontentamento, representado nas figuras indistintas de um certo índio ou um negro, que são historicamente marginalizadas e cujos gritos são vistos nas máscaras. A máscara parece ensejar uma coesão simbólica, aparentemente necessária para se destacar da normalidade e da normatividade em que o corpo está inscrito, aqueles traços que se pretende assinalar como únicos, singulares, importantes. 0 interessante da máscara é que ela não depende do rosto que se esconde, pelo menos não as máscaras vistas nessa e em outras manifestações de ruas. Não importa se quem as veste representa veridicamente um índio ou um negro. Importa sim que aqueles que as carregam reivindicam essas ideias e não outras. 0 corpo parece, então, encontrar na metrópole, com suas camadas temporais e espaciais sobrepostas, uma cenografia convidativa a explorar novas abordagens e atuações de um indivíduo que se vê integrando um corpo social.

Cabe lembrar aqui o arquiteto e artista Flávio de Carvalho, para quem a roupa era de extrema importância - tocava a intimidade dos sujeitos. Em sua autodenominada Experiência 3, de 1956, o artista desfilou pelas ruas do centro de São Paulo com seu traje de verão (minissaia, blusa bufante, meia arrastão - que não aparece na fotografia selecionada para este artigo, e sandálias) causando enorme estranheza. Carvalho nos desafiou a pensar nas práticas vestimentares de um novo jeito, não mais assujeitadas às modas francesas, tão ao gosto eurocêntrico das nossas elites locais. A imagem de Flávio vestindo o traje de verão nas ruas (Figura 2) foi divulgada pela mídia da época e é de fácil acesso hoje via agências de jornalismo, como a Folhapress. É curioso que pouco tenha sido dito a respeito desse traje, além do fato de ele ter sido parte importante da performance do artista que convidava 
os homens a abandonarem a subordinação insensata aos ditames da moda estrangeira e inadequada ao clima tropical.

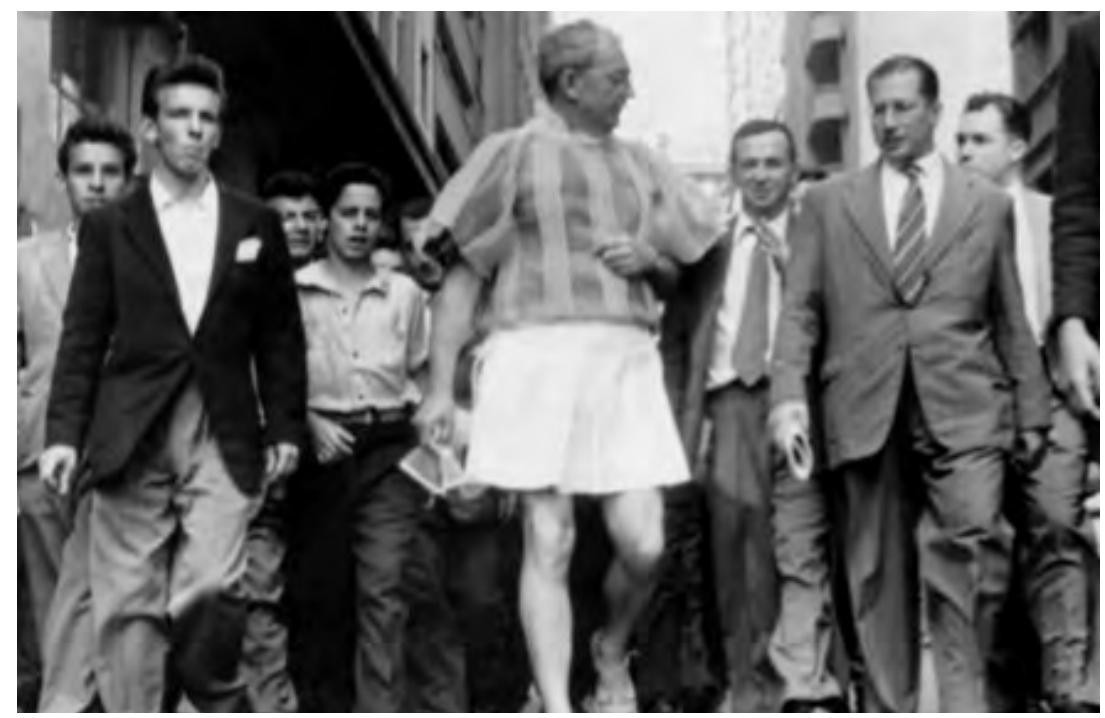

Figura 2 - Flávio de Carvalho em sua Experiência 3, de 1956, vestindo seu traje de verão (sem meias arrastão) em uma rua do centro de São Paulo. Publicado em 18/10/1956, no jornal Última Hora. Fonte: Acervo UH/Folhapress.

Sua ação poética, que aqui denominaremos de micropolítica - ações que confrontam poderes coercitivos no cotidiano -, nos contaminou com uma benfazeja dúvida: a de que é possivel se desencaixar de modos de existência submissos, fazendo ventilar pelo campo social outros desejos, outros universos de referência. Flávio disparou, com o seu traje de verão, uma discussão de grande amplitude: não só podemos pensar como posicioná-la nos trópicos, mas, além disso, nos indagarmos sobre os modos de existência que desejamos neles afirmar.

Ainda que pareça prevalecer um vetor de moda que fixa modelos de representação mais próximos dos centros de poderio econômico e, portanto, político, buscando construir identidades clone que emanam desses grandes centros, há, em contrapartida, práticas de moda e arte desterritorializantes que se disseminam por aí. Nossa contemporaneidade assiste a processos culturais flutuantes. A própria ideia de cultura hoje traz poucos contornos tangiveis. Além disso, nossa condição mestiça, e não iremos nos aprofundar nisso aqui, pode potencializar em nós possiveis vertentes de criação polifônicas. Referimo-nos mais ao hibridismo que se opera entre culturas, suas aproximações e tensões. Falamos de conexões de mundos que contrastam e diferem entre si, e inventam novos arranjos que reposicionam a ideia de matrizes formadoras portuguesa + indígena + africana.

0 anonimato criado com o uso de determinadas roupas, de certos modos de vestir, nos coloca ainda diante de um efeito colateral ao objetivo maior das manifestações populares. 0 padrão resultante do uso de uma espécie de uniforme para a manifestação de rua parece limitar nossa treinada capacidade de classificar as aparências pelas suas identidades nacionais. As imagens 
de pessoas vestidas de calça, camiseta e rosto coberto confundem qualquer tentativa de relacionar a roupa com algum pertencimento nacional.

A estreita relação entre roupa, moda e políticas nacionais é um aspecto discutido no campo dos estudos de moda com insistência. A história da moda, por exemplo, estabeleceu a mentalidade do vestido-nação como um marco teórico que foi amplamente aceito por especialistas, e ainda é. Para registrar alguns exemplos, citamos obras de referência adotadas em cursos de formação superior no Brasil, como os livros de James Laver (1988) e François Boucher (2010), que dividem a história da moda cronologicamente e por nacionalidade, ou por culturas especificas ${ }^{7}$. Assim, temos a indumentária egípcia, a grega, a romana, a francesa etc. Apesar dos traços comuns entre diversas culturas e nações que são notáveis por suas roupas, as diferenças são quase sempre marcadas como índice de distinção cultural, em geral atreladas à nacionalidade.

0 tema moda e nacionalismo continua sendo explorado tanto em países que têm tradição na historiografia da moda, como Inglaterra e França, quanto naqueles chamados de não ocidentais pela literatura especializada. Podemos destacar duas publicações recentes que trazem essa abordagem nacionalista associada à moda e ao vestir. Uma delas é uma enciclopédia mundial da moda publicada em 2010 e que procura cobrir globalmente 0 tema do ponto de vista histórico ${ }^{8}$. Com dez volumes, essa enciclopédia munI5 ] dial inclui diversos artigos divididos por regiões geográficas amplas, como as Américas, a África e a Rússia.

Outra publicação que merece destaque é uma coletânea que reúne trabaIhos de pesquisa sobre a temática da política relacionada aos modos de vestir especificamente nas regiões da Ásia e da América9 ${ }^{9}$ Na introdução do volume, as editoras justificam a escolha de explorar essas duas regiões:

\footnotetext{
0 princípio básico de que a vestimenta é um componente importante da política formal, poderia ser igualmente aplicado à miríade de culturas e nações mundiais. Apesar disso, há pontos específicos da história e de determinados locais no mundo que possuem um escopo altamente fértil para explorar a intersecção entre as forças políticas e as roupas a partir de uma perspectiva transcultural e transnacional. As histórias de muitas nações da Ásia e da América apresentam um rico material deste tipo. (RACE; EDWARDS, 2007, p. 2) ${ }^{10}$
}

Talvez o recorte Ásia e América indique a permanência do exotismo na historiografia da moda desses lugares, mas este não é o ponto mais importante para os objetivos deste presente artigo. 0 que importa aqui é destacar que há situações e condições bastante especiais no uso de determinadas roupas e nas funções dadas a elas que transcendem a persistente questão nacional tradicionalmente associada à história da moda e da indumentária. Transcendem ainda o hibridismo comumente associado aos modos de vestir nas Américas e 
na Ásia, ou nos países não ocidentais. No caso das roupas que associamos às ações poéticas e políticas neste artigo, não seriamos capazes de fornecer indices exóticos ou híbridos que pudessem servir de identificação estética nacional.

Investigar as roupas associadas às recentes manifestações populares parece ser um terreno fértil para explorar novas possibilidades de pesquisa, além daquela que lida com as questões nacionais e culturais relativas ao hibridismo e mestiçagem. Essas questões são relevantes especialmente nas situações em que, como no caso do Brasil, há uma experiência colonial que não pode ser ignorada. Porém, assim como observou Renato Ortiz (2016) ao falar sobre as "imagens do Brasil", é preciso avançar também para outras bandas. Poderíamos, por exemplo, refletir sobre os índices ético-estéticos dessa nova configuração global como uma forma de entrever problemas ou outras questões de interesse social coletivo, que supera ou transcende os contornos geopolíticos.

É possivel pensar que cada vez mais publicações que insistem em se inserir em uma tradição de abordagem da História da Moda, ambicionando apresentar ao estudante uma cronologia em que as perspectivas nacionais e culturais são ressaltadas, contribuem pouco para emancipar o aluno da obrigatoriedade dessa visão historicista, que ainda prevalece como se fosse a mais legitima para os estudos da moda. Decerto, não queremos aqui contestar a importância desses livros, afinal fomos formados a partir dessas leituras. No entanto, elas não parecem mais caber em um mundo que demanda cada vez mais de cada um de nós um olhar microscópico, mais envolvido com as práticas do vestir no cotidiano. Claro que os grandes relatos históricos têm sua importância fundadora, mas talvez nos tragam poucas noticias sobre os modos de subjetivação na atualidade, em que a roupa ganha contornos mais desterritorializantes, inclassificáveis, sobretudo se associada à dimensão que nos interessa mais particularmente aqui, a das manifestações populares. Mas não só. Há também uma força de criação que se dissemina hoje entre alguns criadores de moda mais comprometidos em desencadear com suas roupas intervenções no entorno, no âmbito da cidade contemporânea, por excelência tão complexa e tão polifônica.

Parece-nos que é exatamente essa potência de criação que está presente na marca Universeless ${ }^{11}$, de Lika Stein. Apresentada conceitualmente como uma instigação pós-industrial, produz roupas a partir da ideia central de interferir sobre objetos industrializados, como camisetas, saias, casacos. Com palavras de ordem que aparecem como título para o conjunto de suas criações desde 2006 - DESCONSTRUA/ EXPANDA/ REGOZIJE -, Lika Stein faz um exercício de incorporar a contribuição do Outro e adensar sua criação, exercitando um tipo de procedimento colagístico aplicado à moda que encontra na cidade seu principal mote de criação. Dificil hoje pensar em uma cidade regida pelo princípio da unidade. Por ela transitam os mais diversos sujeitos que vão inventando modos de usá-la inesperados. A imagem que prevalece hoje das cidades que habitamos é a de um espaço multidimensional, heteróclito, descentrado. 


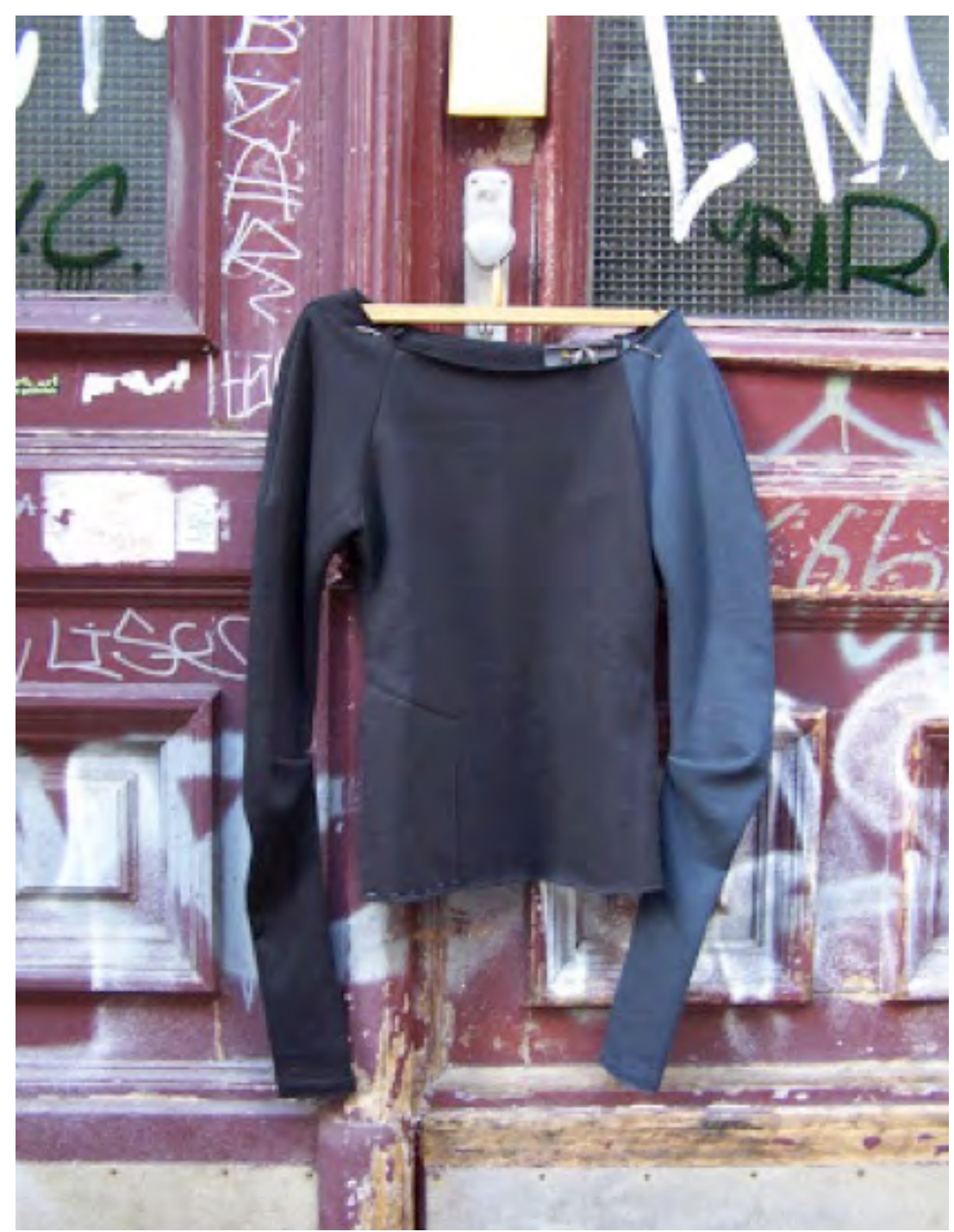

Figura 3 - Imagem de roupas na cidade: moletom cinza + moletom duas cores, 2011. Fonte: Blog Universeless ${ }^{12}$.

Lika veste a cidade, seus cinzas, a aglomeração e o caos urbano. Ela recolhe o que a cidade expele, seus restos, e os sobrepõe ao corpo, fazendo com que o corpo, com eles, entre em conversações. Os tons da cidade migram para a roupa, tingindo-a organicamente (Figura 3). Suas roupas se propõem de algum modo a promover a interlocução entre as pessoas e nos fazem relembrar que a rua é local de encontros. Parecem responder às mudanças que vão se processando na vida e no campo social, e daí resulta uma experimentação de moda que deseja se consolidar olhando de perto o que acontece, na contramão de discursos de moda que fixam tendências para atender a demandas mercadológicas. Suas criações parecem se distanciar significativamente das práticas mais recorrentes em moda, na medida em que a estilista assume um protagonismo estético e político ao colocar sua criação a serviço de um posicionamento na existência. Sua pesquisa de formas é decorrente de sua vivência na cidade, esta que abraça uma dimensão política, ou, talvez dito de forma mais precisa, micropolítica, na medida em que se trata de microrrevoluções no cotidiano, por vezes quase imperceptíveis e, no entanto, vitais para expandir o campo social.

Ouvindo os últimos acontecimentos de ocupação das ruas, no Brasil e no mundo, atentos às ações dos black blocs, talvez possamos dizer que as roupas 
de Lika convergem para esse diálogo, renovado com outras perspectivas de criação mais sintonizadas com as cidades e seus fluxos cotidianos que thes servem de suporte. Criar, então, se traduziria em modos de escutar afinados com a complexidade do contemporâneo, composta por paisagens hibridas e cada vez menos sujeitas a lógicas lineares de interpretação. No que diz respeito à moda, à criação de roupas, como não pensá-la menos conformada às lógicas univocas do fazer moda? As roupas coexistem com as cidades. Cabe lembrar brevemente aqui do vestuário projetado pelo futurista italiano Giacomo Balla, para quem a roupa era indissociável da movimentação da cidade. Era exatamente seu dinamismo e seu ritmo que ele desejava transmitir por meio de suas estampas. A vanguarda futurista era por demais atenta e sensivel a essa interlocução arte-vida, e Balla fazia da roupa um suporte singular que sustentasse essa possibilidade de manifestação.

Tanto as roupas de protesto usadas pelos black blocs quanto as de Lika Stein nos arremessam em outros territórios e nos estimulam a pensar a criação de roupas a partir de outras soluções plásticas, formas, volumes, texturas. Nesse sentido, a roupa nos auxilia a perceber como vamos sendo - o uso do gerúndio nos é importante porque capta a dimensão processual da subjetividade - e de que modo vamos dialogando com o mundo ao nosso redor. Um modo singular que vai interceptando as formas prontas de vestir, que recorrentemente reproduzimos.

É preciso, portanto, escutar as vozes que destoam das visões mais homogêneas da moda. A vida dificilmente cabe em discursos restritivos, cujo imperativo, e aqui tomamos como referência o funcionamento do capitalismo neoliberal, é vender modos de vestir que se cruzam com modos de existir, os quais sufocam de antemão o espaço necessário para que outros referenciais ético-estéticos se formulem. Pelo fato de tudo ter de caber o mais rápido possível em um nome próprio, prontamente assimilável e catalogável, é preciso lançar mão de palavras de ordem, logo, afirmar certezas, forjar coerências e evitar a todo custo imprecisões e ambiguidades. Não podemos esquecer que tudo virá previamente legendado, mastigado, pronto para ser usado e multiplicado.

Claro que tudo que se descola das formas prontas, estabilizadas, da sensibilidade acostumada, fora dos espelhos que só nos refletem e dão apenas testemunho de um mundo acanhado em que cabem poucos, nos inquieta bastante. No entanto, talvez devêssemos saudar aquilo que não podemos nomear porque escapa aos códigos hegemônicos do vestir, os embaralha e nos força a pensar para além dos modelos instituídos pelos quais transitamos em suposta segurança. E ainda que tenhamos uma sensação de que predominam subjetividades dóceis que se comprazem em reproduzir valores, estão certamente por aí, a se engendrar em silêncio, na surdina, experimentações que escapam às padronizações.

Recebido em: 15-05-2017

Aprovado em: 24-07-2017 


\section{NOTAS}

${ }^{1}$ Apresentamos as reflexões iniciais sobre este tema no Simpósio 10 - OUTRAS: práticas e pensamentos em deslocamento -, durante $023^{\circ}$ Encontro Nacional da Associação Nacional de Pesquisadores em Artes Plásticas (ANPAP), Ecossistemas Artísticos, realizado no periodo de 15 a 19 de setembro de 2014, em Belo Horizonte (MG).

2 Para o cientista político Edson Passetti, professor do programa de pós-graduação em Ciências Sociais da PUC-SP, os black blocs são uma atualização dos movimentos anarquistas do começo do século XX. Suas táticas anticapitalistas vêm se disseminando por várias capitais mundiais, no decorrer do século XX, alcançando os dias atuais. Em entrevista realizada por Bruno Pontes, Prática aglutina gente em torno do insuportável, publicada em O Povo on-line. Disponível em: <http://www.opovo.com.br/app/opovo/politica/2013/08/10/ noticiasjornalpolitica,3108577/pratica-aglutina-gente-em-torno-do-insuportavel.shtml>. Acesso em: 3 maio 2015.

${ }^{3}$ Gustavo Goulart e Antônio Werneck. PF investiga atuação de grupos anarquistas baseados no Rio. Relatório alerta para a possibilidade de ocorrerem protestos violentos no próximo mês. In: 0 Globo, 11/10/2013. Rio de Janeiro. Disponivel em: <http://oglobo.globo.com/rio/pf-investiga-atuacao-de-grupos-anarquistas-baseados-norio-10332014\#ixzz2qDhdeTBH>. Acesso em: 3 maio 2015.

${ }^{4}$ Foto: REUTERS/Ricardo Moraes. 0 Globo, 30/8/2013. Disponivel em: <http://noticias.r7.com/rio-de-janeiro/ projeto-de-lei-pode-proibir-uso-de-mascaras-em-manifestacoes-no-rio-30082013 >. Acesso em: 3 maio 2015.

${ }^{5}$ Disponivel em: <http://content.time.com/time/magazine/0,9263,7601111226,00.html>. Acesso em: 3 maio 2015.

${ }^{6}$ Fonte: Marco Antônio Martins. Mascarados podem ir a protesto de 7 de Setembro, diz secretário de Segurança do Rio. In: Folha de S. Paulo (versão digital), 6/9/2013, às 13h09. Disponivel em: <http://folha.com/no1337930>. Acesso em: 3 maio 2015.

${ }^{7}$ LAVER, James. A roupa e a moda: uma história concisa. São Paulo: Companhia das Letras, 1982 (1936). BOUCHER, François. História do vestuário no Ocidente. São Paulo: Cosac Naify, 2012.

${ }^{8}$ Essa enciclopédia pretendeu investigar a história da moda inclusive em paises de pouca tradição nessa área, os chamados paises não ocidentais. Esta expressão traz alguns problemas conceituais que não discutiremos aqui. EICHER, Joanne B. Berg's. Encyclopaedia of World Dress and Fashion. Bloomsbury, 2010.

${ }^{9}$ ROCES, Mina Roces; EDWARDS, Louise (Eds.). The politics of dress in Asia and the Americas (series The Sussex Library of Asian \&t Asian American Studies). Sussex Academic, 2007.

${ }^{10}$ Tradução livre das autoras do trecho: "The basic principle that dress is an important component of formal politics could apply equally across the world's myriad cultures and nations. Yet, there are specific points in history and particular global locations that present highly fertile scope for exploring the intersection between political forces and dress from a trans-cultural and trans-national perspective. The histories of the many nations comprising Asia and the Americas provide just such rich material". (RACE; EDWARDS, 2007, p. 2)

${ }^{11}$ Disponivel em: http://universeless.blogspot.com.br. Disponivel em: 3 maio 2015.

${ }^{12}$ Disponivel em: <http://universeless.blogspotcom.br/search/label/roupas\%20cidade\%20kleidung\%20clothes\%20 jumpers. Acesso em: 3 maio 2015. 


\section{REFERÊNCIAS}

BERENSTEIN, Paola. Corpografias urbanas: o corpo enquanto resistência. In: Resistências e Espaços Opacos, Cadernos PPG - FAUUFBA. Salvador, 1998.

BOLLON, Patrice. A moral da máscara. Rio de Janeiro: Rocco, 1997.

CAMILLO OSÓRIO, Luiz. Eu sou apenas um! In: Cadernos Vídeo Brasil - performance. São Paulo, 2005.

CARVALHO, Flávio. A moda e o novo homem. Rio de Janeiro: Azougue Editorial, 2010.

CERQUEIRA, Monique Borba. Pobres, resistência e criação. São Paulo: Editora Cortez, 2010.

CERTEAU, Michel de. A invenção do cotidiano - 1. Artes do fazer. Petrópolis: Editora Vozes, 2003.

CESARINO, Pedro; REZENDE, Renato; COHN, Sergio (Orgs.). Tunga. Azougue, edição especial 2006-2008, Rio de Janeiro, 2008.

COELHO, Teixeira. A cultura e seu contrário: cultura, arte e política pós-2001. São Paulo: Editora Iluminuras/ Itaú Cultural, 2008.

CORRÊA LEITE, José; CARVALHO de, Mônica; SEABRA, Odette. Território e sociedade: entrevista com Milton Santos. 2. ed. 3. reimpr. São Paulo: Editora Fundação Perseu Abramo, 2007.

DELEUZE, Gilles. Diálogos. São Paulo: Editora Escuta, 1998.

LIMA, Eduardo Rocha. Três esquizos literários. Porto Alegre: Editora Sulina, 2010.

MIGNOLO, Walter D. Novas reflexões sobre a "ideia da América Latina": a direita, a esquerda e a opção descolonial. In: Caderno CRH, v. 21, n. 53, Salvador, maio/ago. 2008. Disponivel em: <http://dx.doi. org/10.1590/S0103-49792008000200004>. Acesso em: 10 jan. 2014.

The idea of Latin America. Oxford: Blackwell, 2005.

ORTIZ, Renato. Imagens do Brasil. In: Revista Sociedade e Estado, v. 28, n. 3, set./dez. 2013, pp. 609-633.

PELBART, Peter Pál. A vertigem por um fio: políticas da subjetividade contemporânea. São Paulo: Editora Iluminuras/ FAPESP, 2000.

PINHEIRO, Amálio. Notas sobre conhecimento e mestiçagem na América Latina. In: MESOUITA, C. E PRECIOSA, R. (Orgs.). Moda em ziguezague - interfaces e expansões. Barueri: Editora Estação das Letras e Cores, 2011.

PRECIOSA, Rosane. Errância, contaminações, fluxos esquizos. Revista Visualidades, v. 10, n. 2, Goiânia, pp. 57-73, jul./dez. 2012 (publicado em 2013).

Moda brasileira, lugar de contaminações. 9 Colóquio de Moda, Fortaleza, 2013.

Rumores discretos da subjetividade: sujeito e escritura em processo. Porto Alegre: Editora Sulina/ UFRGS, 2010.

ROCES, Mina Roces; EDWARDS, Louise (Eds.). The politics of dress in Asia and the Americas (series The Sussex Library of Asian \&t Asian American Studies). Sussex Academic, 2007.

ROLNIK, Suely. Subjetividade antropofágica/ Anthropophagic Subjectivity. In: HERKENHOFF, P. E; PEDROSA, A (Eds.). In: Arte contemporânea brasileira: Um e/entre Outro/s, XXIV Bienal Internacional de São Paulo. São Paulo: Fundação Bienal de São Paulo, 1998. pp. 128-147. Disponivel em: <http://www. pucsp.br/nucleodesubjetividade/Textos/SUELY/Subjantropof.pdf $>$. Acesso em: 15 set. 2013.

SALOMÃO, Waly. Homage. In: OITICICA, H. Catalogue de la Gallerie Nationale du Jeu de Paume, 1992.

SCHECHNER, Richard. A rua é o palco. In: LIGIÉRO, Z. (Org.). Performance e antropologia de Richard Schechner. Rio de Janeiro: Editora Mauad X, 2012, pp. 155-198.

VIANNA, Hermano. Além do Ocidente. Segundo Caderno, 0 Globo, 27/7/2012. Disponivel em: <http:// hermanovianna.wordpress.com/2012/07/28/alem-do-ocidente>. Acesso em: 10 nov. 2013. 